\title{
Green manufacturing dimensions and global trends of consumption
}

\author{
Vasile Popa ${ }^{1}$ and Luminiţa Popa ${ }^{2, *}$ \\ ${ }^{1}$ National Defence University "Carol I", Regional Department of Defense Resources Management \\ Studies Mihai Viteazul, No. 160, Braşov, Romania \\ ${ }^{2}$ Transilvania University of Braşov, Department of Automation and Information Technologies, \\ Mihai Viteazul 5, Braşov, Romania
}

\begin{abstract}
The article addresses the issue of green manufacturing in the context of global trends of consumption for various types of industrial products, respecting the concepts of circular economy. The article focuses on impact of global trends of consumption on green manufacturing dimensions (research and design process, waste control, packaging control, manufacturing control and quality control) of Romanian industry sustainable development. The authors have achieved a "correlation matrix of green manufacturing dimensions and global trends of consumption for production systems".
\end{abstract}

\section{Introduction}

In essence, sustainable consumption involves "the use of goods and services that satisfy basic needs and achieve a better quality of life, while minimizing the consumption of natural resources, the generation of toxic materials and the emission of increase waste recovery and pollutants on during a life cycle, so there is no risk inability to meet the general needs of future generations "(WBCSD, 2008) [1].

\section{Sustainable consumption and circular economy}

The sustainable consumption requires social needs satisfaction only at a decent quality of life and does not affect the quality of life increase, contrary. Green industrial products consumption can take place only through efficient use of resources, widespread use of renewable energy and minimizing waste (circular economy concepts).

In terms of technology and natural ecology, a circular economy has two characteristics. First characteristic is technological feature (green manufacturing dimension). The second characteristic is the systematic feature.

The circular economy is a systematic and holistic economic operation involving every field and every link in the production chain of social value [2]. Green Manufacturing dimensions" and" Global trends of green industrial products consumption" are shwon in Table 1.

\footnotetext{
${ }^{*}$ Corresponding author and co-author(s): vasilepopa2001@yahoo.com
} 
Table 1. The Matrix of "Green Manufacturing dimensions" and"Global trends of green industrial products consumption"

\begin{tabular}{|c|c|c|c|c|c|c|c|c|c|c|c|c|c|c|}
\hline \multirow{2}{*}{ No } & & \multicolumn{11}{|c|}{ Global trends of green industrial products consumption } & \multirow[b]{2}{*}{ 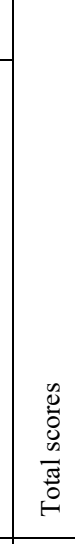 } & \multirow[b]{2}{*}{$\begin{array}{l}\text { o } \\
0 \\
0 \\
0 \\
0 \\
0 \\
0 \\
0 \\
0\end{array}$} \\
\hline & $\begin{array}{l}\text { Green } \\
\text { manufac- } \\
\text { turing } \\
\text { dimensions }\end{array}$ & 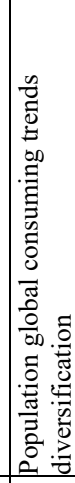 & 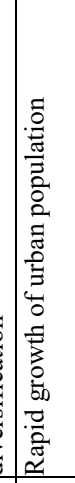 & 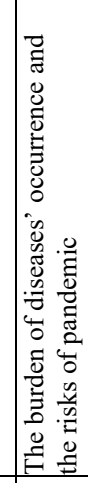 & 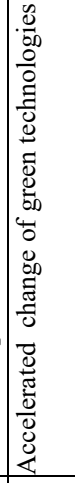 & 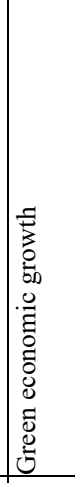 & 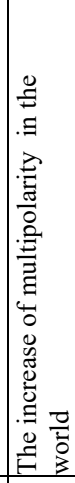 & 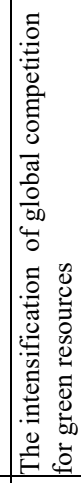 & 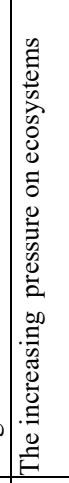 & 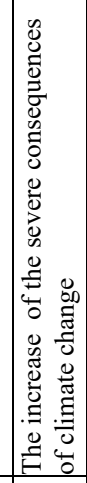 & 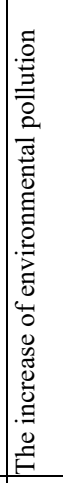 & 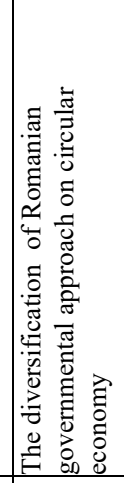 & & \\
\hline & (1) & (2) & (3) & (4) & (5) & (6) & (7) & (8) & (9) & $(10)$ & (11) & $(12)$ & (13) & (14) \\
\hline 1 & $\begin{array}{l}\begin{array}{l}\text { Research and } \\
\text { design process }\end{array} \\
\end{array}$ & $\mathrm{X}$ & $\mathrm{X}$ & $\mathrm{X}$ & $\mathrm{X}$ & $\mathrm{X}$ & $\mathrm{X}$ & $\mathrm{x}$ & $\mathrm{X}$ & $\mathrm{X}$ & $\mathrm{X}$ & $\mathrm{x}$ & 11 & 26.19 \\
\hline 2 & $\begin{array}{l}\text { Production } \\
\text { control }\end{array}$ & & - & & $\mathrm{X}$ & $\mathrm{X}$ & & $\mathrm{X}$ & $\mathrm{X}$ & & $\mathrm{X}$ & $\mathrm{X}$ & 6 & 14.28 \\
\hline 3 & $\begin{array}{l}\text { Quality } \\
\text { control }\end{array}$ & $\mathrm{x}$ & $\mathrm{X}$ & $\mathrm{X}$ & $\mathrm{X}$ & $\mathrm{X}$ & & $\mathrm{X}$ & $\mathrm{X}$ & & $\mathrm{X}$ & $\mathrm{X}$ & 9 & 21.43 \\
\hline 4 & $\begin{array}{l}\text { The packaging } \\
\text { control }\end{array}$ & $\mathrm{X}$ & $\mathrm{X}$ & 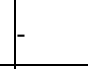 & $\mathrm{x}$ & $\mathrm{x}$ & $\mathrm{x}$ & $\mathrm{x}$ & & - & & $\mathrm{X}$ & 7 & 16.67 \\
\hline 5 & Waste control & $\mathrm{X}$ & $\mathrm{X}$ & $\mathrm{X}$ & $\mathrm{X}$ & $\mathrm{x}$ & 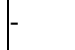 & 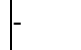 & $\mathrm{X}$ & $\mathrm{X}$ & $\mathrm{X}$ & $\mathrm{x}$ & 9 & 21.43 \\
\hline \multicolumn{2}{|c|}{ Total scores } & 4 & 4 & 3 & 5 & 5 & 2 & 4 & 4 & 2 & 4 & 5 & 42 & 100 \\
\hline \multicolumn{2}{|c|}{$\begin{array}{l}\text { Weighted scores } \\
(\%)\end{array}$} & 9.52 & 9.52 & 7.14 & 11.90 & 11.90 & 4.76 & 9.52 & 9.52 & 4.76 & 9.52 & 11.90 & 100 & 100 \\
\hline
\end{tabular}

The global trends of green industrial products consumption are shown in Figure 1.

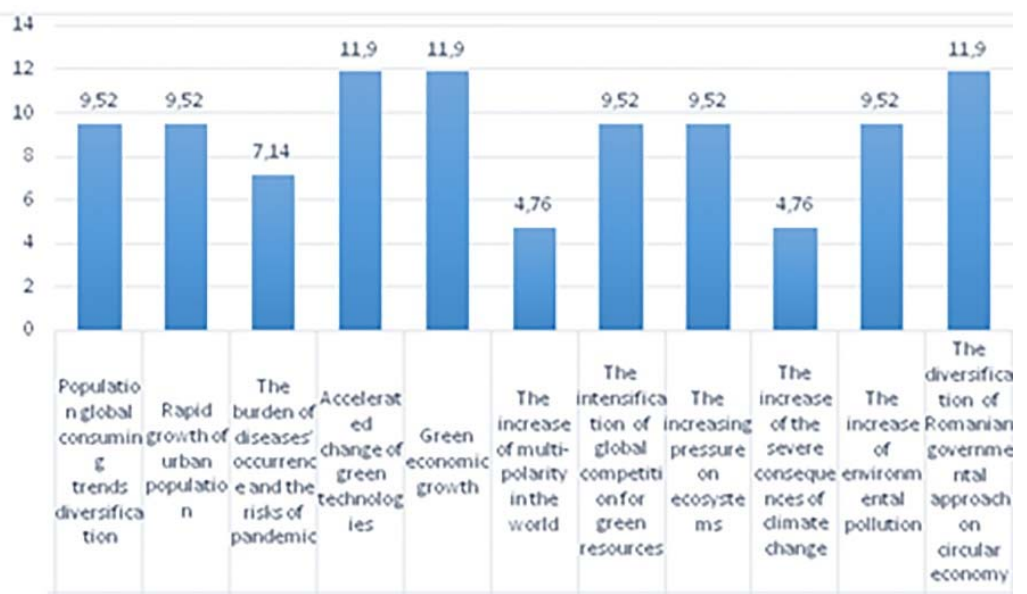

Fig. 1. Global trends of green industrial products consumption. 
As we can see in the Figure 1, three of "Global trends of green industrial products consumption" named "Accelerated change of green technologies", "Green economic growth" and "The diversification of Romanian governmental approach on circular economy" have the highest weighted score $(11.90 \%)$. All these three consumption trends have a strong "green" component. In this case, the companies' managers, who are trying to implement circular economy in Romania, need to take in consideration these three consumption trends of Romanian population because they could affect our country GDP (Gross Domestic Product) for the next years. The green manufacturing dimensions are shown in Figure 2.

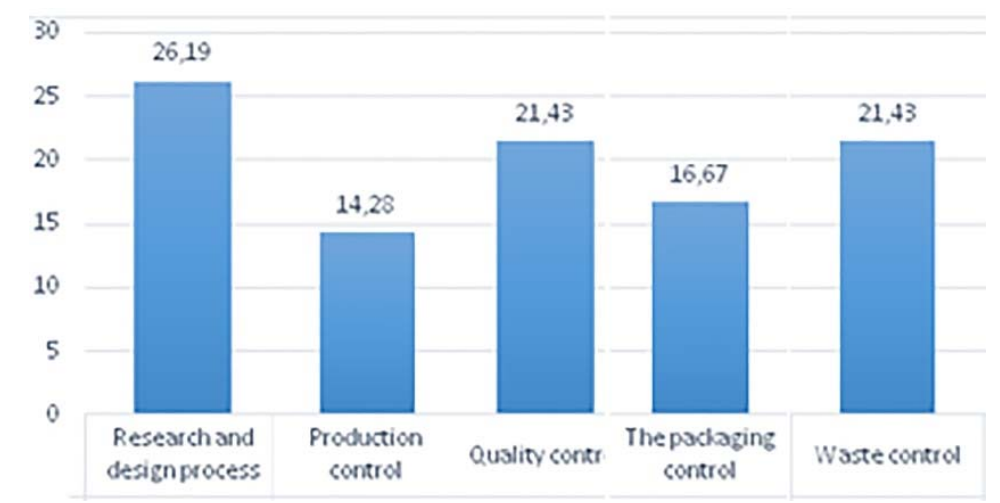

Fig. 2. Green manufacturing dimensions.

As we can see in the Figure, one of "Green manufacturing dimensions" named "Research and design process" has the highest weighted score $(26.19 \%)$. We consider that this is a very important issue for companies' managers who are trying to achieve Romanian industry sustainable development. Also another two "Green manufacturing dimensions" ("Waste control" and"Quality control') have a high weighted score (21.43\%) The Romanian industry sustainable development could be obtained only if we take in consideration these control issues in the near future.

\subsection{Population global consuming trends diversification}

The measure package on circular economy requires commitment of the EU and its Member States to achieve the UN target of halving a high sustainable food waste level by 2030.

To support this objective, the hierarchy of use of the food should be a guiding principle in managing food resources, and this action should be supported by economic incentives in all relevant EU policies. The package of measures on circular economy also identifies the need to clarify the current guidance on the use as animal feed food not fit for human consumption. A solid Romanian circular economy legislation, which is regulating new sterilization technologies of food waste through an industrial centralized process, could ensure microbiological safety of animal feed, while creating new jobs and investment opportunities and taking full environmental benefits a more effective application of the waste hierarchy. The globalization and economic integration are causing a wider and easier access to more products and services. The economic globalization makes the world economy to be dominated by uncontrollable market forces, its main economic actors and change agents are big transnational companies which are not subject to any state and which are situated on the world market where outweigh the benefits. The world's economies remain highly interconnected through trade, investment and financial systems. Consumer confidence is one of the key driving factors for GDP growth [3]. 


\subsection{Rapid growth of urban population}

Globally, the number and size of cities continues to rise - the trend is fueled by rapid urbanization from emerging markets and continues urbanization from mature markets. According to UN data, 54\% of the world population lives in cities, and by 2050 this proportion will increase to $66 \%$ [4]. An effective strategy for the challenges facing cities, including climate change and poverty, will be crucial for the future development of cities which have to be competitive, sustainable and reliable. Globally, the facilities offered by modern human society such as those related to modern medicine, better conditions of life, etc., caused an important decrease of infant mortality and overall mortality rate of human population.

\subsection{The burden of diseases' occurrence and the risks of pandemic}

Urban sprawl, population growth, global travel and rudimentary systems for providing health services in poor countries are showing that global pandemics issues continue to pose a serious threat to the health of human civilization. The Public Health - which already represent $10 \%$ of global GDP - is on the verge of an epochal transformation. Health systems and payers are subjected to increasing pressure of cost, exacerbated by demographic changes, revenue growth in fast growing markets and an impending epidemic of chronic diseases. The aging of the population will overwhelm the system. Ageing will lead to an increase in the number of people suffering from illnesses and chronic conditions and who require expensive treatments, requiring within healthcare systems. As a result of this demographic phenomenon, serious problems will arise.

\subsection{Accelerated change of green technologies}

The green technology is covering a broad group of materials and constantly evolving methods and practices for generating energy from non-toxic cleaning products. Extent of new green technologies exploded in the last two decades. The green technology is almost entirely a science-based material. Based on the availability of alternative sources of energy, the goal of this technology is to reduce global warming and the greenhouse effect. Its main objective is to find ways to create new technologies, avoiding damage or depletion of natural resources of the planet. The green technology is a ecological technology developed and used in a way that does not damage the environment and conserve natural resources. Based on the availability of alternative sources of energy, the goal of this technology is to reduce emissions of greenhouse pollutants, preserve natural resources, eliminating or reducing pollution emissions. All energy sources affect the environment. There is no energy source completely "green".

\subsection{Green economic growth}

The economic prospects remain highly uncertain and risks are rising overall. Among these include the economic downturn in emerging markets, a disorderly adjustment in China and the possibility of higher interest rates in the United States to distort the markets financial or emerging economies vulnerable to damage and affect prospects. A new decline in oil prices could also have a negative effect on countries oil exporters and could lead to reduced demand for EU exports. Green economic growth potential has diminished both in advanced economies and in the emerging economies. 


\subsection{The increase of multipolarity in the world}

The increasing of multi-polarity in the world belongs to fundamental international political system. The national power will not be able to impose its own regulatory objectives; it will gain more power international agencies and transnational organizations. The distinct disciplinary powers of nation-states will decline, even if the majority of their citizens, especially the advanced countries will remain nationally attached. Military power becomes less efficient and no longer used for economic goals because state control of the economy disappears.

\subsection{The intensification of global competition for green resources}

The depletion of important mineral resources is imminent. This situation has made a number of scientific personalities to draw more frequent alarm sounding about the precarious state of the natural environment and the need for rapid and radical changes in terms of our attitude towards the environment and towards the issue of development, starting from present technologies and strategies. The population growth in absolute values, economic development and the rise of middle-class consumers will feed the increasing global demand for natural resources - both renewable and non-renewable. While nonrenewable resources of the planet are finite technically, new technologies continue to change the picture of the supply of resources in the future by new possibilities of accessing reserves of oil, gas and minerals that were previously difficult to access. The application of new technologies and the changing landscape of supply will facilitate the adaptation of circular economy business models. Increasing concerns about environmental degradation, the need to preserve strategic green resources and ensuring our food and water resources indicates that protect and preserve the planet are imperative for the future.

\subsection{The increasing pressure on ecosystems}

The pressure on natural resources is measured by Ecological Footprint. The Ecological Footprint is a synthetic indicator of the pressure that humans exert on the natural environment, mainly through production and consumption. It measures how much land and how much water people need to produce goods and services required consumption (food, shelter and other), how much land is needed for infrastructure and to absorb CO2 that human civilization it generates - from the perspective of preserving biocapacity global natural. Decrease the environmental footprint of carbon emissions must be a top priority to avoid dangerous climate change. This can be reduced by increasing energy efficiency, boosting electricity as an energy source and replacing fossil fuels with biofuels.

\subsection{The increase of the severe consequences of climate change}

The climate change is the only global pressure factor with direct impact on all other factors. Financial losses arising from climate change are projected to be $1 \%$ per year if preventive actions are taken sustained and timely, and at least $5 \%$ per year if policymakers do not act accordingly.

\subsection{The increase of environmental pollution}

The pollution is changing the natural components through the presence of foreign components, called pollutants as a result of human activity, and causing harmful effects on health, cause discomfort or prevent the use of environmental components which are 
essential to life. It follows from the definition can be seen clearly that the greatest responsibility for environmental pollution belongs to man, the pollution being the consequence of human economic-social activity. Initiative, such as the Kyoto agreement, is an objective for a healthy world. Currently, in most countries in Europe and in much of the world, Building Regulations are set to achieve this goal. It is a great opportunity for companies to realize more than "being green" - which is a necessity for all companies today.

\subsection{The diversification of Romanian governmental approach on circular economy}

The governmental measures are aimed at restructuring the pricing system, so that environmental costs to be properly reflected in the price of goods and services. The role of companies producing goods and services becomes, under circular economy circumstances, more decisive. These companies must show social responsibility to contribute to economic development by improving the quality of life in the workplace, but also in the local communities and society in general, allowing sustainable development not only in the economic dimension but also in the social and environmental dimensions. Romanian companies can address sustainable consumption and changing lifestyles in ways such as innovation, influencing choice etc.

\section{Conclusions}

The trade and economic relations are based on currently connectivity and communication. Achieving a green industrial products sustainable consumption require changing measures of demand structures and current life styles, as restricting the inclination to perform certain excesses, especially in economically developed countries, where the share of population with higher income is more consistent. Promoting sustainable consumption and development can be done by various companies of a series of products and services that maximize social value and minimize environmental effects. The green manufacturing dimensions as circular economy principles can be promoted by educating and influencing the choice by consumers of goods and services. The renewable sources in Romania have the most competitive advantages and opportunities. Despite this fact and despite the significant potential for the development of this sector in Romania (the largest wind potential in Europe), these are only approached as another way of obtaining energy, not as one to which we should give priority.

\section{References}

1. World Business Council for Sustainable Development, Sustainable Consumption Facts and Trends. From a business perspective (2008)

2. B. Su, A. Heshmati and Y. Geng, A Review of the Circular Economy in China: Moving from Rhetoric to Implementation (2013), downloaded from:http://www.akes.or.kr/eng/papers\%282012\%29/7.full.pdf

3. CEDEFOP, Skills Supply and Demand in Europe - Medium term forecast up to 2020, downloaded from www.cedefop.europa.eu/files/3052_en.pdf

4. World Urbanisation Prospects. The 2014 Revision, Department of Economic and Social Affairs (United Nations, 2014) 